JAMP: Jurnal Adminitrasi dan Manajemen Pendidikan

Volume 3 Nomor 2 Juni 2020, Hal : 160-170

Tersedia Online di http:/journal2.um.ac.id/index.php/jamp/

ISSN 2615-8574 (online)

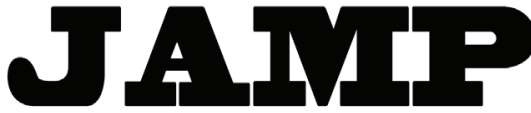

JURNAL ADMINISTRASI DAN MANAJEMEN PENDIDIKAN

\title{
DAMPAK PEMBELAJARAN BERKARAKTER TERHADAP PENGUATAN KARAKTER SISWA GENERASI MILENIAL
}

\author{
Sultoni \\ Imam Gunawan \\ Hasan Argadinata
}

Universitas Negeri Malang, Jalan Semarang 5 Malang 65145
Email: imam.gunawan.fip@um.ac.id

\begin{abstract}
The purpose of this study was to determine the effect of character learning variables $(\mathrm{X})$ on the strengthening of student character $(\mathrm{Y})$. The study was conducted using the quantitative-causality method. The instrument used to measure the research variables was a questionnaire. The research sample was 80 Islamic Junior High School teachers in Jombang Regency. Analysis of the data used is descriptive and simple regression. The results of descriptive analysis of the data show: the character learning variable $(\mathrm{X})$ is included in the quite good category with an average of 96.71 ; and the student character strengthening variable $(\mathrm{Y})$ is included in the quite good category with an average of 55.33. The results of a simple regression analysis showed that there was an influence of the character learning variable $(\mathrm{X})$ on the strengthening of student character $(\mathrm{Y})$. The resulting regression coefficients are: $\hat{\mathrm{Y}}=$ $10.496+0.464 \mathrm{X}$. The contribution of character learning variable $(\mathrm{X})$ to the strengthening of student character (Y) was $23.3 \%$.
\end{abstract}

Keywords: learning character, strengthening student character, millennial generation

\begin{abstract}
Abstrak: Tujuan penelitian ini adalah untuk mengetahui pengaruh variabel pembelajaran berkarakter $(\mathrm{X})$ terhadap penguatan karakter siswa $(\mathrm{Y})$. Penelitian dilaksanakan dengan metode kuantitatif-kausalitas. Instrumen yang digunakan untuk mengukur variabel penelitian adalah angket. Sampel penelitian adalah 80 orang guru Madrasah Tsanawiyah (MTs) Kabupaten Jombang. Analisis data yang digunakan adalah deskriptif dan regresi sederhana. Hasil analisis deskriptif data menunjukkan: variabel pembelajaran karakter $(\mathrm{X})$ termasuk dalam kategori cukup baik dengan rerata 96,71; dan variabel penguatan karakter siswa (Y) termasuk dalam kategori cukup baik dengan rerata 55,33. Hasil analisis regesi sederhana menunjukkan terdapat pengaruh variabel pembelajaran berkarakter $(\mathrm{X})$ terhadap penguatan karakter siswa $(\mathrm{Y})$. Koefisien regresi yang dihasilkan adalah: $\hat{Y}=10,496+0,464 X$. Kontribusi variabel pembelajaran berkarakter $(\mathrm{X})$ terhadap penguatan karakter siswa $(\mathrm{Y})$ sebesar $23,3 \%$.
\end{abstract}

Kata kunci: pembelajaran berkarakter, penguatan karakter siswa, generasi milenial

Karakter merupakan hal yang krusial harus dimiliki oleh setiap insan manusia. Seiring dengan perkembangan jaman, siswa yang pada masa sekarang ini lazim disebut sebagai generasi milenial, juga harus memiliki karakter kuat, agar ia tidak tercerabut dari akar budaya luhur bangsa Indonesia. Pembelajaran yang diselenggarakan oleh sekolah saat ini harus dapat memahami karakteristik siswa generasi milenial. Karakteristik utama generasi milenial adalah pemanfaatan internet yang dominan. Karakteristik generasi milenial adalah sadar secara sosial; berbasis teknologi; merangkul pengalaman dan pengeluaran etis; terdidik dan berpengetahuan; sadar kesehatan; sadar keuangan; dan sadar secara spiritual (Cheng, 2019; Argadinata \& Gunawan, 2019). Liu, dkk., (2019) berdasarkan hasil kajiannya merekomendasikan kepada para peneliti untuk mengeksplorasi karakteristik unik dari generasi milenial yang dikaitkan dengan kewirausahaan, serta pengaruhnya terhadap motivasi wirausaha, orientasi, penemuan peluang dan proses eksploitasi, dan ambisi global dari usaha wirausaha mereka. 
Penelitian ini fokus pada mengkaji pembelajaran berkarakter yang berupaya mengaitkan penguatan karakter siswa generasi milenial. Penelitian yang dilakukan oleh Boyles (2018) fokus pada kegiatan membaca dan menganalisis teks pada anak sekolah dasar dalam mengembangkan pembelajaran berkarakter. Membaca dan menganalisis teks dengan siswa sekolah dasar adalah cara sempurna untuk memperkenalkan pertanyaan yang lebih besar tentang cara siswa berinteraksi satu sama lain dan dunia yang lebih besar. Boyles (2018) membahas bagaimana mengajar pembelajaran sosial-emosional melalui literatur dapat dengan mudah dimasukkan ke dalam rutinitas membaca yang sudah ada, dengan menyertakan tiga buku bergambar sampel dengan pertanyaan analisis berbasis pembelajaran sosialemosional dan panduan untuk mengajar.

Pembelajaran berkarakter merupakan pembelajaran yang mengutamakan tantangan, kerja tim, layanan, kasih sayang, dan fokus pada pembelajaran siswa aktif berbasis penyelidikan. Pembelajaran berkarakter menempatkan karakter siswa di pusat pekerjaan sekolah (Kusumaningrum, dkk., 2019a; Bafadal, dkk., 2019). Prestasi yang tinggi dari siswa adalah hasil dari tingkat keterlibatan dan etika kerja yang tidak biasa yang ditimbulkan oleh pendekatan sekolah terhadap guru ditambah dengan budaya akademik, misalnya pola pikir akademik dan strategi pembelajaran. Faktor-faktor ini bergabung untuk mendukung keberhasilan siswa dari semua latar belakang di sekolah, teman sebaya, dan kehidupan keluarga.

Siswa di sekolah dipupuk dalam tiga dimensi, yaitu: (1) ukuran pencapaian tradisional, misalnya ujian nasional, penerimaan perguruan tinggi; (2) penciptaan karya berkualitas tinggi yang bercita-cita untuk standar profesional; dan (3) penanaman kekuatan karakter untuk mencapai kehidupan yang sukses, memuaskan dan berbudi luhur (Gunawan, dkk., 2020). Gunung yang didaki oleh siswa adalah gunung metaforis yang mengarah pada keberhasilan akademis, tetapi etika yang sama berlaku: semua siswa harus saling mendukung dan memaksa satu sama lain untuk mencapai puncak dan untuk mencapai lebih dari yang mereka pikir mungkin. Dewasa ini akibat perkembangan jaman, memunculkan sikap persaingan yang dominan dalam diri orang, dan mengakibatkan karakter kolaboratif perlahan terkikis dari interaksi sosial manusia. Karakter kolaboratif saling bekerjasama dalam arti positif merupakan penting untuk selalu ditanamkan kepada siswa, sebab manusia merupakan makhluk sosial yang dependen satu sama lain dan saling terkoneksi.

Studi Wing-YinChow (2018) menguatkan pembelajaran yang berpusat pada membaca dan pengembangan literasi siswa dapat menjadi model pembelajaran berkarakter yang baik untuk menguatkan karakter siswa. Studi ini telah memberikan dukungan untuk model pengembangan literasi yang menemukan bahwa membaca awal dengan mengandalkan metode pembelajaran holistik, yang secara bertahap berubah menjadi pendekatan analitik untuk pembelajaran akan meningkatkan pengalaman belajaran dalam membaca menjadi berkembang. Shen (2005) berdasarkan hasil analisis regresi menunjukkan bahwa ada tren linier antara tingkat pembelajaran berkarakter dan persepsi siswa tentang kegunaan strategi dalam membangun kelompok belajar.

Pembelajaran berkarakter yang dimaksud dalam penelitian ini adalah pembelajaran yang memiliki indikator: (1) variasi sumber pembelajaran; (2) seimbang integritas dengan utilitas; (3) tanggung jawab belajar setiap siswa; (4) pergeseran peran sekolah; (5) adanya kontradiksi; (6) adanya investasi untuk mengembangkan siswa; dan (7) daya nalar dan kritis (Mawarsari \& Solichan, 2015). Ketujuh indikator tersebut dapat digunakan dan/atau dikembangkan lebih lanjut bagi peneliti, guru, pendidik, atau praktisi pendidikan dalam meneliti pembelajaran berkarakter. Peran guru dalam pembelajaran berkarakter sangat menentukan keberhasilan, terutama untuk menguatkan karakter siswa.

Bahasan tentang penguatan karakter siswa tak akan usang oleh perkembangan jaman, sebab karakter generasi mendatang ditentukan oleh karakter generasi saat ini yang sedang menempuh pendidikan (siswa, mahasiswa, peserta didik). Berbagai kebijakan pun juga telah dirancang oleh pemerintah untuk menguatkan karakter siswa, baik pada level sekolah dasar sampai dengan perguruan tinggi. Pemerintah melalui Kementerian Pendidikan Nasional tahun 2010 merancang kebijakan karakter yang harus ditanamkan kepada siswa, yakni ada 18 karakter yang mencakup: (1) religius; (2) jujur; (3) toleransi; (4) disiplin; (5) kerja keras; (6) kreatif; (7) mandiri; (8) demokratis; (9) rasa ingin tahu; (10) semangat 
kebangsaan; (11) cinta tanah air; (12) menghargai prestasi; (13) bersahabat / komunikatif; (14) cinta damai; (15) gemar membaca; (16) peduli lingkungan; (17) peduli sosial; dan (18) tanggung jawab (Kementerian Pendidikan Nasional, 2010).

Kemudian tahun 2017 melalui Kementerian Pendidikan dan Kebudayaan melakukan restrukturisasi pendidikan karakter dengan Gerakan Penguatan Pendidikan Karakter, yakni mereduksi 18 karakter menjadi 5 karakter yang mencakup: (1) religius; (2) nasionalisme; (3) integritas; (4) kemandirian; dan (5) kegotongroyongan (Kementerian Pendidikan dan Kebudayaan, 2017). Penguatan karakter siswa yang dimaksud dalam penelitian ini adalah dengan mengacu pada 18 jenis karakter. Penguatan karakter siswa merupakan aspek yang penting sebagai upaya strategis dalam menguatkan budaya bangsa. Karakter siswa menjadi program yang perlu menjadi perhatian secara holistik bagi penyelenggara pendidikan, sebab siswa saat ini adalah calon pemimpin bangsa ini. Siswa yang berkarakter merupakan modal kuat guna membentuk peradaban bangsa yang kuat.

Dan upaya tersebut akan berhasil manakala pembelajaran juga dilaksanakan dengan mengacu pada karakter-karakter tersebut. Pembelajaran berkarakter adalah pembelajaran yang diselenggarakan dengan mengacu pada kaidah-kaidah normatif dan holistik, sehingga membentuk siswa menjadi pribadi yang kuat karakternya, halus hatinya, kuat kemauannya, dan gemilang prestasinya. Pembelajaran berkarakter harus dirancang dengan baik oleh guru, dengan bantuan kepala sekolah, sehingga pembelajaran akan benar-benar merdeka dari kegiatan administratif yang idealnya tidak boleh dominan, dan pembelajaran berkarakter dapat terlaksana dengan berlandaskan pada penguatan berpikir, berperilaku, dan bertindak pada diri siswa. Hal itulah inti dari tujuan pendidikan, yakni menyentuh aspek sikap, pengetahuan, dan keterampilan. Ketiga domain tersebut harus dimiliki oleh setiap siswa secara seimbang.

Guna melaksanakan pembelajaran berkarakter, guru juga perlu memahami tentang pendekatan manajemen kelas (Suminah, dkk., 2018; Gunawan, dkk., 2018; Gunawan, 2011), dan juga guru harus memperhatikan motivasi belajar siswa (Sultoni, dkk., 2018b), sebab pendekatan manajemen kelas dan motivasi belajar siswa juga dapat mempengaruhi siswa dalam belajar. Lingkungan sekolah yang sehat mampu mendukung karakter siswa dengan gaya hidup sehat (Andriningrum \& Gunawan, 2018), sebab dengan lingkungan sekolah yang sehat, akan tercipta suasana menyenangkan bagi siswa yang dapat memicu siswa belajar dengan nyaman. Karakter ditentukan oleh apa yang dilakukan, bukan apa yang dikatakan atau yakini oleh seseorang.

Setiap pilihan yang seseorang buat membantu menentukan jenis orang yang dipilih oleh seseorang. Karakter yang baik membutuhkan melakukan hal yang benar, bahkan ketika itu mahal atau berisiko. Seseorang tidak harus mengambil perilaku terburuk dari orang lain sebagai standar perbandingan untuk diri sendiri. Seseorang dapat memilih untuk menjadi lebih baik dari itu. Apa yang dilakukan seseorang itu penting, dan satu orang bisa membuat perbedaan besar. Imbalan untuk memiliki karakter yang baik adalah itu membuat seseorang menjadi orang yang lebih baik dan itu membuat dunia menjadi tempat yang lebih baik. Tujuan utama penelitian ini adalah untuk mengetahui pengaruh variabel pembelajaran berkarakter $(\mathrm{X})$ terhadap penguatan karakter siswa $(\mathrm{Y})$. Hipotesis yang diajukan dalam penelitian ini adalah terdapat pengaruh variabel pembelajaran berkarakter $(\mathrm{X})$ terhadap penguatan karakter siswa $(\mathrm{Y})$.

\section{METODE}

Mengacu pada tujuan penelitian, rancangan penelitian ini adalah kuantitatif-kausalitas, yakni untuk mengetahui pengaruh variabel pembelajaran berkarakter (X, sebagai variabel prediktor) terhadap penguatan karakter siswa (Y, sebagai variabel kriterium). Rancangan penelitian kuantitatif-kausalitas berupaya menyelidiki relasi sebab-akibat dari variabel prediktor terhadap variabel kriterium. Penelitian dilaksanakan pada rentang bulan September 2018. Populasi penelitian ini adalah 624 orang guru Madrasah Tsanawiyah (MTs) Kabupaten Jombang. Sampel yang diambil sejumlah 80 orang guru, dengan teknik quota random sampling.

Instrumen yang digunakan adalah angket. Angket disusun dengan mengacu pada indikator variabel penelitian. Indikator tersebut dirancang sesuai dengan teori pembelajaran berkarakter (ada 7 indikator) 
dan penguatan karakter siswa (ada 18 indikator). Angket disusun dengan pernyataan positif. Responden dalam mengisi angket dengan memilih pilihan jawaban sesuai dengan kondisi responden. Skala pilihan jawaban angket mengacu pada skala Likert, yakni: selalu (SL) diberi skor 4; sering (SR) diberi skor 3; jarang (JR) diberi skor 2; dan tidak pernah (TP) diberi skor 1.

Berdasarkan tujuan penelitian, data peneliti ini dianalisis dengan: (1) statistik deskriptif, yakni menghitung rerata, deviasi standar, skor tertinggi, skor terendah, dan selanjutnya disajikan deskripsi frekuensi setiap variabel penelitian dengan mengacu pada rumus stanfive (Tabel 1); dan (2) analisis regresi sederhana. Data sebelum dianalisis dengan regresi sederhana, terlebih dahulu diuji normalitas, homogenitas, dan linieritas untuk mengetahui apakah data memenuhi asumsi data yang dapat dianalisis dengan statistik parametrik (analisis regresi sederhana). Hasil analisis regresi sederhana selain digunakan untuk menguji hipotesis, juga dijadikan dasar merumuskan persamaan regresi dan menghitung kontribusi variabel prediktor terhadap variabel kriterium. Rumus persamaan regresi adalah $\hat{Y}=a+b X$ (Gunawan, 2013; Gunawan, 2016; Hadi, dkk., 2018). Sedangkan rumus menghitung kontribusi variabel prediktor terhadap variabel kriterium adalah $\mathrm{R}^{2}$ x 100\% (Gunawan, 2013; Gunawan, 2016; Hadi, dkk., 2018). Semua analisis data menggunakan bantuan program IBM SPSS Statistics 24.

Tabel 1 Rumus Stanfive

\begin{tabular}{cll}
\hline No & \multicolumn{1}{c}{ Formula Rumus } & \multicolumn{1}{c}{ Kategori } \\
\hline 1 & $(\overline{\mathrm{X}}+\mathbf{1 , 5} \mathrm{DS})<\mathrm{X}$ & Sangat baik \\
2 & $(\overline{\mathrm{X}}+\mathbf{0 , 5} \mathrm{DS})<\mathrm{X}<(\overline{\mathrm{X}}+\mathbf{1 , 5} \mathrm{DS})$ & Baik \\
$\mathbf{3}$ & $(\overline{\mathrm{X}}-\mathbf{0 , 5} \mathrm{DS})<\mathrm{X}<(\overline{\mathrm{X}}+\mathbf{0 , 5} \mathrm{DS})$ & Cukup baik \\
4 & $(\overline{\mathrm{X}}-\mathbf{1 , 5} \mathrm{DS})<\mathrm{X}<(\overline{\mathrm{X}}-\mathbf{0 , 5} \mathrm{DS})$ & Kurang baik \\
$\mathbf{5}$ & $\mathrm{X}<(\overline{\mathrm{X}}-\mathbf{1 , 5} \mathrm{DS})$ & Tidak baik \\
\hline Sumber: Wiyono dan Sunarni $(2009)$ &
\end{tabular}

\section{HASIL}

\section{Deskripsi Data}

Berdasarkan hasil perhitungan data variabel pembelajaran karakter $(X)$ diketahui: rerata 96,71; deviasi standar 12,56; skor maksimum 133; dan skor minimum 64. Berdasarkan hasil perhitungan dengan menggunakan rumus stanfive (Tabel 1), diketahui deskripsi frekuensi variabel pembelajaran karakter (X) seperti pada Gambar 1. Berdasarkan pada Gambar 1 diketahui responden yang berada pada skor: $<77,87$ sebanyak 4 orang (5\%); 77,87 s.d. 90,43 sebanyak 22 orang (27,5\%); 90,43 s.d. 102,99 sebanyak 26 orang (32,5\%); 102,99 s.d. 115,56 sebanyak 26 orang (32,5\%); dan > 115,56 sebanyak 2 orang $(2,5 \%)$. Mengacu pada rerata $(96,71)$ disimpulkan variabel pembelajaran karakter $(\mathrm{X})$ termasuk dalam kategori cukup baik.

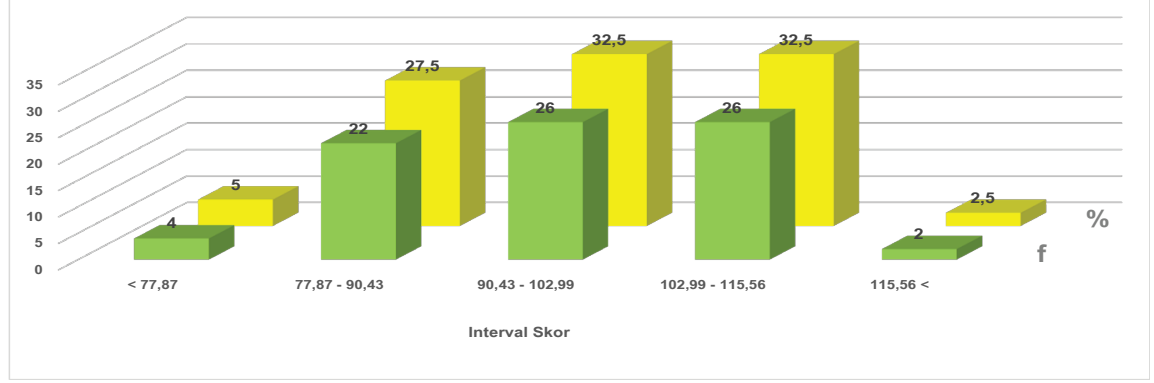

Gambar 1 Distribusi Frekuensi Variabel Pembelajaran Karakter (X) 
Berdasarkan hasil perhitungan data variabel penguatan karakter siswa (Y) diketahui: retata 55,33; deviasi standar 12,05; skor maksimum 72; dan skor minimum 18. Berdasarkan hasil perhitungan dengan menggunakan rumus stanfive (Tabel 1), diketahui deskripsi frekuensi variabel penguatan karakter siswa (Y) seperti pada Gambar 2. Berdasarkan pada Gambar 2 diketahui responden yang berada pada skor: < 37,25 sebanyak 5 orang (6,25\%); 37,25 s.d. 49,3 sebanyak 14 (17,5); 49,3 s.d. 61,35 sebanyak 33 orang $(41,25)$; 61,35 s.d. 73,4 sebanyak 28 orang (35\%); dan tak ada responden pada skor $>73,4$. Mengacu pada rerata $(55,33)$ disimpulkan variabel penguatan karakter siswa (Y) termasuk dalam kategori cukup baik.

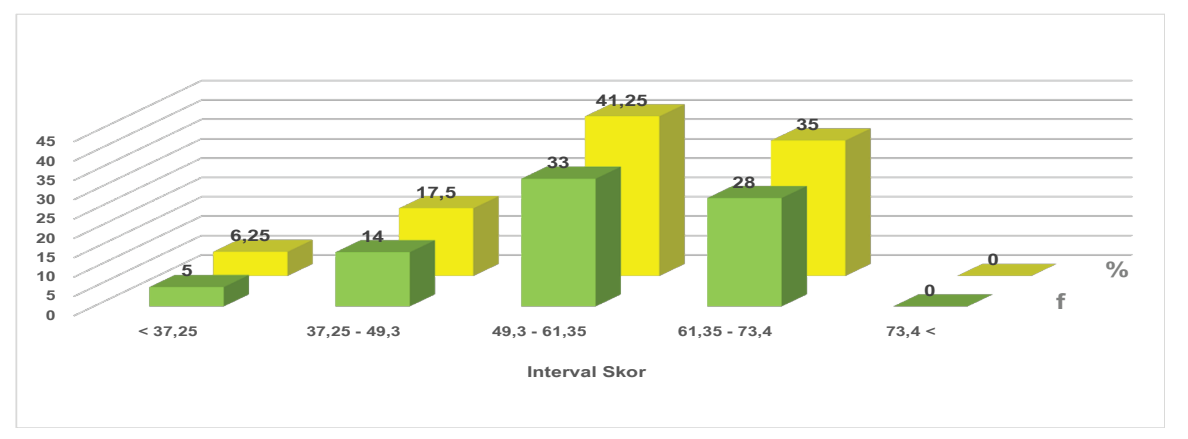

Gambar 2 Distribusi Frekuensi Variabel Penguatan Karakter Siswa (Y)

\section{Uji Asumsi Data}

Data sebelum dianalisis dengan analisis regresi sederhana, diuji normalitas, homogenitas, dan linieritas, sebab analisis regresi merupakan statistik parametrik yang tidak bebas distribusi. Uji normalitas digunakan untuk mengetahui data penelitian memenuhi kaidah kurva normal. Uji normalitas dengan menggunakan kolmogorov-smirnov test (Gunawan, 2013; Gunawan, 2016; Hadi, dkk., 2018). Berdasarkan uji kolmogorov-smirnov test diketahui Asymp. Sig. (2-tailed) variabel pembelajaran karakter (X) sebesar 0,993 dan variabel penguatan karakter siswa (Y) sebesar 0,540. Berdasarkan nilai Asymp. Sig. (2-tailed) kedua variabel $>0,05$; sehingga disimpulkan data penelitian termasuk dalam kategori normal.

Uji homogenitas digunakan untuk mengetahui data penelitian memiliki varians yang relatif kecil. Uji homogenitas dengan menggunakan test of homogeneity of variances (Gunawan, 2013; Gunawan, 2016; Hadi, dkk., 2018). Berdasarkan uji test of homogeneity of variances diketahui nilai signifikansi levene statistic variabel pembelajaran karakter $(\mathrm{X})$ sebesar 0,043 dan variabel penguatan karakter siswa (Y) sebesar sebesar 0,001. Berdasarkan nilai signifikansi levene statistic kedua variabel $<0,05$; sehingga disimpulkan data penelitian memiliki varians yang relative kecil (data homogen).

Uji linieritas digunakan untuk mengetahui data penelitian variabel $\mathrm{X}$ dan $\mathrm{Y}$ mengikuti kaidah garis linieritas. Uji linieritas dengan menggunakan uji curve estimation test (Gunawan, 2013; Gunawan, 2016; Hadi, dkk., 2018). Berdasarkan uji curve estimation test diketahui nilai signifikansi relasi variabel $\mathrm{X}$ terhadap $\mathrm{Y}$ sebesar 0,000 . Nilai curve estimation test relasi kedua variabel $<0,05$; sehingga disimpulkan relasi kedua variabel mengikuti kaidah linier. Berdasarkan hasil uji asumsi data yang mencakup normalitas, homogenitas, dan linieritas, data penelitian memenuhi untuk dianalisis dengan menggunakan regresi sederhana.

\section{Uji Hipotesis}

Hipotesis yang diuji adalah ada pengaruh yang signifikan pembelajaran berkarakter $(\mathrm{X})$ terhadap penguatan karakter siswa (Y). Formula yang digunakan untuk menguji hipotesis tersebut adalah uji t. Hasil analisis uji t memeroleh nilai signifikansi sebesar 0,000 (Tabel 2). Berdasarkan hasil analisis uji dengan nilai signifikansi sebesar 0,000 ; diketahui nilai signifikansi $0,000<0,05$; sehingga Ho ditolak, disimpulkan ada pengaruh yang signifikan pembelajaran berkarakter $(\mathrm{X})$ terhadap penguatan karakter 
siswa (Y). Selanjutnya ditentukan formula persamaan regresi sederhana relasi kedua variabel dengan menggunakan pedoman Tabel 2 Coefficients. Berdasarkan Tabel 2 Coefficients diperoleh persamaan regresi kedua variabel adalah:

$\hat{Y}=10,496+0,464 X$

Berdasarkan persamaan regresi kedua variabel tersebut dapat dijelaskan bahwa: konstanta sebesar 10,496 menyatakan bahwa jika tidak terdapat kenaikan skor dari pembelajaran berkarakter (X), maka skor penguatan karakter siswa (Y) adalah sebesar 10,496. Koefisien regresi sebesar 0,464 untuk variabel pembelajaran berkarakter $(\mathrm{X})$ menyatakan bahwa setiap penambahan satu skor pembelajaran berkarakter (X) akan memberikan kenaikan sebesar 0,464 terhadap penguatan karakter siswa (Y).

Tabel 2 Coefficients

\begin{tabular}{ccccccc}
\hline \multirow{2}{*}{ Model } & \multicolumn{2}{c}{ Unstandardized Coefficients } & $\begin{array}{c}\text { Standardized } \\
\text { Coefficients }\end{array}$ & t & \multirow{2}{*}{ Sig. } \\
\cline { 3 - 6 } & & $\mathrm{B}$ & Std. Error & Beta & & \\
\hline \multirow{2}{*}{1} & (Constant) & $\mathbf{1 0 . 4 9 6}$ & $\mathbf{9 . 2 7 3}$ & .132 & .261 \\
\hline & $\mathrm{X}$ & .464 & .095 & .483 & $\mathbf{4 . 8 7 4}$ & .000 \\
\hline
\end{tabular}

a. Dependent Variable: Y

Selanjutnya berdasarkan Tabel 3 Model Summary dihitung kontribusi variabel pembelajaran berkarakter (X) terhadap penguatan karakter siswa (Y). Berdasarkan Tabel 3 Model Summary diketahui koefisien regresi variabel pembelajaran berkarakter $(\mathrm{X})$ terhadap penguatan karakter siswa (Y) sebesar 0,483. Sehingga kontribusi variabel prediktor terhadap variabel kriterium adalah: $\mathrm{R}^{2} \times 100 \%=(0,483)^{2} \times 100 \%=23,3 \%$. Berdasarkan perhitungan tersebut diketahui bahwa kontribusi variabel pembelajaran berkarakter $(\mathrm{X})$ terhadap penguatan karakter siswa (Y) sebesar 23,3\%; sedangkan sisanya $76,7 \%$ adalah variabel lain.

Tabel 3 Model Summary

\begin{tabular}{crrrr}
\hline Model & R & R Square & $\begin{array}{c}\text { Adjusted R } \\
\text { Square }\end{array}$ & $\begin{array}{c}\text { Std. Error of the } \\
\text { Estimate }\end{array}$ \\
\hline 1 & $.483^{\text {a }}$ & .233 & .224 & 10.618 \\
\hline
\end{tabular}

a. Predictors: (Constant), $\mathrm{X}$

\section{PEMBAHASAN}

Penelitian ini menyimpulkan bahwa ada pengaruh yang signifikan pembelajaran berkarakter (X) terhadap penguatan karakter siswa $(\mathrm{Y})$. Kontribusi variabel pembelajaran berkarakter (X) terhadap penguatan karakter siswa (Y) sebesar 23,3\%. Hasil penelitian ini menguatkan pentingnya pembelajaran berkarakter dilaksanakan oleh guru untuk mendukung penguatan karakter siswa, serta capaian siswa dalam pembelajaran, secara holistik mencakup aspek afektif, kognitif, dan psikomotorik. Penelitian ini selaras dengan riset yang dilakukan oleh Irfan (2016) yang menyimpulkan pembelajaran berkarakter dapat membentuk dan menguatkan karakter siswa, yaitu karakter disiplin, kejujuran, adil dan bijaksana, mengasumsikan itikad baik, ketekunan, logis dan rasional, serta kritis dan kreatif. Pembelajaran berkarakter selain fokus pada substansi pembelajaran bidang studi, juga menyampaikan nilai-nilai kehidupan saat pembelajaran, sehingga siswa memiliki karakter yang kuat (Putri, dkk., 2019).

Penguatan karakter siswa pada prinsipnya tidak dapat dipisahkan dari kegiatan pembelajaran, sebab penguatan karakter siswa juga termasuk dalam substansi yang harus diajarkan dan direalisasikan siswa (Direktorat Pembinaan Sekolah Dasar, 2011). Problematika penguatan karakter siswa selama ini adalah masih pada tataran pengenalan norma kepada siswa, belum optimal pada tataran internalisasi, tindakan riil, dan penghayatan pada diri siswa dalam kehidupan. Belajar merupakan proses perubahan tingkah laku dari hasil pengalaman siswa. Intervensi perubahan perilaku siswa yang digunakan oleh guru menunjukkan efektivitas yang terbatas (Dragomir, dkk., 2019; Bergen, 2020), sehingga pembelajaran perlu dirancang agar siswa dapat menerapkan belajar dengan melakukan / learning by doing (Sumarsono, dkk., 2019).

Guru perlu mendefinisikan dan mengidentifikasi ulang ciri-ciri karakter siswa yang penting di sekolah. Guru perlu mengeksplorasi teori, mengidentifikasi keterampilan yang dapat diintegrasikan 
ke dalam kelas, membuat rencana pelajaran, dan menganalisis dan melakukan review pelajaran untuk melihat nilai dan mempromosikan pengembangan karakter pada siswa. Guru dapat menjadi model yang efektif bagi siswa mereka. Guru mengidentifikasi kekuatan karakter pribadi mereka dan mengeksplorasi bagaimana kekuatan ini bekerja untuk membantu guru ketika masalah terjadi di kelas. Kelas ini dimaksudkan tidak hanya untuk sekolah (Hardika, dkk., 2018; Yang, dkk., 2020; Kusumaningrum, dkk., 2019b), tetapi juga untuk kehidupan dan karena itu juga akan melibatkan menjelajahi semua komponen, yakni dengan melibatkan seluruh sekolah, orangtua, dan masyarakat (Sultoni, dkk., 2018a; Nurabadi, dkk., 2019).

Permasalahan penguatan karakter siswa yang telah dikupas sebelumnya, akan dapat diselesaikan secara optimal dengan kerjasama secara integral antara orangtua, guru, sekolah, dan masyarakat (Benty \& Gunawan, 2015). Selaras dengan teori Dewantara (2011a, 2011b) yang membagi fungsi pranata keluarga, sekolah dan masyarakat dalam mengembangkan siswa, yakni: (1) keluarga, berfungsi dalam pembimbingan siswa, yaitu upaya pemantapan pribadi berbudaya keluarga (informal); (2) sekolah, berfungsi dalam pengajaran siswa, yaitu upaya penguasaan pengetahuan sekolah (formal); dan (3) masyarakat, berfungsi dalam pelatihan siswa, yaitu upaya memahirkan keterampilan masyarakat (nonformal). Jika mengacu pada teori tersebut, maka sangat jelas bahwa pranata keluarga (orangtua) yang berfungsi vital dalam penguatan karakter siswa, dengan didukung pranata sekolah dan masyarakat.

Lazim orangtua ingin agar anak mereka tumbuh menjadi pribadi atau individu yang santun, halus hatinya, rendah hati, dan memiliki rasa hormat kepada orang lain. Oleh sebab itu, pembelajaran berkarakter dan pendidikan karakter adalah bagian penting dalam pengembangan diri siswa, karena kesuksesan tidak bergantung pada aspek akademis semata. Benar bahwa alasan orangtua mendaftarkan anak mereka ke sekolah ialah untuk belajar tentang bidang studi yang bersifat akademik, seperti ilmu sosial, matematika, fisika, sejarah, sains, bahasa, dan sebagainya, tetapi bidang studi tersebut bukanlah segala-galanya atau satu-satunya hal yang perlu dipelajari dan dikuasi oleh siswa jika ingin menjadi orang yang sukses dan berhasil. Pembelajaran berkarakter dan pendidikan karakter memberi mereka alat yang diperlukan dan yang akan ia gunakan lebih banyak daripada yang mereka pelajari dari bidang studi itu, untuk mampu hidup di masyarakat dan membangun masyarakat.

Pembelajaran berkarakter adalah metode pengajaran yang mendorong perkembangan siswa menjadi insan yang etis, bertanggung jawab, dan dengan guru sungguh-sungguh mengajar siswa tentang nilai-nilai baik yang seharusnya dimiliki, akan meningkatkan pengembangan diri siswa. Pembelajaran berkarakter mengajarkan siswa tentang nilai kepedulian, kejujuran, simpati, tulus, tanggung jawab, dan sifat-sifat penting lainnya yang membuat mereka menjadi warga masyarakat yang beradab dan bermoral. Keluarga (orangtua) bukanlah satu-satunya pranata yang harus peduli dalam mengembangkan karakter siswa, namun masyarakat dan sekolah juga harus memiliki peran dan fungsi dalam hal ini. Dewasa ini, dengan berbagai faktor, sebagian besar keluarga, anak sering dibiarkan, tanpa adanya proses bimbingan dari keluarga. Hal inilah yang menjadi rasional atau sebab sekolah dan masyrakat juga harus menerapkan pendidikan karakter, dengan harapan siswa mengetahui jalan yang benar.

Pembelajaran berkarakter adalah disiplin ilmu yang berupaya dengan disengaja mengoptimalkan perilaku etis siswa (Agboola \& Tsai, 2012; deRuiter, dkk., 2019). Hasil pembelajaran berkarakter selalu mendorong, solid, dan terus-menerus mempersiapkan para siswa sebagai pemimpin masa depan. Promosi pembelajaran berkarakter tidak hanya sekedar layanan lompatan, tetapi memiliki rencana aksi untuk latihan dan terus mengembangkan substansi pembelajaran. Dengan kata lain, kebijakan pendidikan harus mewujudkan pendidikan moral. Bersama-sama, orangtua, guru, dan administrator sebagai pemangku kepentingan, harus bergabung dengan program ini untuk mendorong siswa mewujudkan nilai-nilai baik itu dalam kehidupan mereka. Kepala sekolah dalam hal memiliki posisi strategis dengan kepemimpinan pembelajarannya guna mendukung guru mampu menerapkan pembelajaran bermakna (Sobri, dkk., 2018; Bafadal, dkk., 2018a; Bafadal, dkk., 2018b; Sobri, dkk., 2019).

Penelitian dari pembelajaran berkarakter dan pendidikan karakter yang dilakukan oleh Lewis (2017) menunjukkan bahwa di sekolah yang memasukkan pendidikan karakter, hasilnya sepadan, yaitu: (1) mengurangi kekerasan dan intimidasi; (2) disiplin tinggi; (3) meningkatkan kehadiran siswa; (4) optimalnya kerja sama dalam menyelesaikan konflik antarpribadi; (5) peduli kepada orang lain; (6) meningkatkan nilai ujian dan optimalnya pekerjaan rumah; (7) meningkatkan keterampilan komunikasi 
siswa; dan (8) meningkatkan keterlibatan siswa dalam kegiatan sekolah. Setiap aspek layanan sekolah dilaksanakan dengan berlandaskan pada perilaku baik (Prastiawan, dkk., 2019; Pambudi \& Gunawan, 2019; Hartini, dkk., 2012), guna menanamkan karakter kuat pada diri siswa (Tryanasari, dkk, 2013).

Pendidikan karakter akan terus diperlukan, walaupun jaman akan terus berkembang, sebab pada kenyataannya pembelajaran sekolah diperlukan oleh keluarga dan masyarakat secara berkelanjutan. Siswa perlu ditunjukkan contoh-contoh karakter yang baik dan konstan, yakni dengan mempraktikkan apa yang dipelajari dan apa yang ideal. Adanya proses tersebut merupakan hal yang diperlukan untuk menanamkan sifat-sifat karakter yang baik pada siswa. Sekolah adalah tempat yang sempurna untuk menanamkan nilai-nilai moral di dalamnya, sebab siswa menghabiskan sebagian besar waktu mereka di sekolah. Selain itu, tujuan siswa diajarkan karakter yang baik adalah untuk membantu mempersiapkan siswa menghadapi banyak peluang dan tantangan yang ada di masyarakat saat ini. Pendidikan karakter dan pembelajaran berkarakter memberikan siswa pengetahuan yang mereka butuhkan untuk mengetahui problematika serta tantangan apa yang ada di masyarakat dan menanganinya dengan benar.

Para siswa saat ini mudah sekali terpapar pengaruh negatif dari isi media sosial (Wiyono, dkk., 2019) dan teman sebaya mereka setiap hari. Hal tersebut menambah fakta menyedihkan bahwa orangtua menghabiskan waktu lebih sedikit dengan anak-anak. Siswa perlu tahu bagaimana menangani tekanan ini. Dan tekanan itu mampu diantisipasi dengan adanya program pendidikan karakter serta guru menerapkan pembelajaran berkarakter. Pendidikan karakter dan pembelajaran berkarakter memberi siswa alat yang ia butuhkan ketika ia hidup di tengah-tengah masyarakat, dengan berbagai ragam perbedaan yang ada. Pendidikan karakter dan pembelajaran berkarakter membantu siswa untuk bersikap baik dalam mempelajari mata pelajaran akademik, agar ia nantinya tidak menyalahgunakan ilmu yang ia dapatkan di kemudian hari. Ketekunan, jujur, gemar membaca, peduli, dan rasa tanggung jawab adalah beberapa nilai inti utama yang diajarkan dalam pendidikan karakter. Siswa juga harus fokus belajar tentang bidang studi yang mereka tekuni. Dan yang lebih penting adalah para siswa memiliki kemauan untuk terus belajar dan belajar.

Membangun karakter juga membantu mereka untuk berinteraksi dengan guru dan sesama siswa, mengubah ruang kelas mereka menjadi lingkungan belajar yang lebih baik. Penelitian yang dilakukan McLean, dkk., (2020) pada subjek siswa menemukan bahwa sekolah yang memiliki program pendidikan karakter memiliki tingkat disiplin tinggi, suspensi, dan meningkatkan kehadiran siswa di kelas. Lingkungan positif sekolah-sekolah juga meningkatkan kehadiran dan juga membawa peningkatan yang signifikan dalam kinerja akademik para siswa (Gunawan, dkk., 2017; Samsiyah, dkk., 2016; Gunawan, dkk., 2016). Apa yang dipelajari siswa dari pendidikan karakter akan bermanfaat bagi mereka ketika mereka terlibat dan berinteraksi dengan orang lain di masyarakat. Agar mereka menjadi anggota terhormat komunitas mereka, mereka perlu mengetahui cara yang tepat untuk memperlakukan orang lain, dan ini adalah hal-hal yang mereka pelajari dan pahami melalui pendidikan karakter.

\section{SIMPULAN}

Hasil analisis deskriptif data menunjukkan bahwa kedua variabel penelitian variabel pembelajaran karakter dan variabel penguatan karakter siswa termasuk dalam kategori cukup baik. Hasil uji hipotesis dengan analisis regesi sederhana menunjukkan terdapat pengaruh variabel pembelajaran berkarakter terhadap penguatan karakter siswa. Hasil penelitian ini menguatkan pentingkannya pembelajaran berkarakter yang berlandaskan pendidikan karakter untuk menguatkan karakter siswa. Siswa yang memiliki karakter kuat merupakan sebuah modal besar bagi bangsa Indonesia masa depan di tengah percaturan peradaban dengan bangsa-bangsa lain di dunia ini. Peran guru menjadi vital dalam penguatan karakter siswa dengan menerapkan pembelajaran berkarakter. Penguatan karakter siswa akan lebih optimal ketika orangtua, sekolah, dan masyarakat bekerja sama yang terintegrasi dalam penyelenggaraan pendidikan bagi siswa. 


\section{DAFTAR RUJUKAN}

Agboola, A., \& Tsai, K. C. (2012). Bring Character Education into Classroom. European Journal of Educational Research, 1(1), 163-170.

Andriningrum, A., \& Gunawan, I. (2018). Cultivatation of Healthy Life for Students in School: A Literature Review. Proceedings of the International Conference on Education and Technology (ICET 2018), Atlantis Press.

Argadinata, H., \& Gunawan, I. (2019). The Leadership of Pancasila in Education: Foundation for Strengthening Student Characters in the Industrial Revolution Era 4.0. Proceedings of the 4th International Conference on Education and Management (COEMA 2019), Atlantis Press.

Bafadal, I., Juharyanto, J., Nurabadi, A., \& Gunawan, I. (2018a). Principal Leadership and its Relationship with Student Learning Achievements: A Regression Analysis. Proceeding the 3rd International Conference on Educational Management and Administration (CoEMA 2018), Atlantis Press.

Bafadal, I., Nurabadi, A., \& Gunawan, I. (2018b). The Influence of Instructional Leadership, Change Leadership, and Spiritual Leadership Applied at Schools to Teachers'Performance Quality. Proceeding the International Conference on Education and Technology (ICET 2018), Atlantis Press.

Bafadal, I., Nurabadi, A., Sobri, A. Y., \& Gunawan, I. (2019). The Competence of Beginner Principals as Instructional Leaders in Primary Schools. International Journal of Innovation, Creativity and Change, 5(4), 625-639.

Benty, D. D. N., \& Gunawan, I. (2015). Manajemen Hubungan Sekolah dan Masyarakat. Malang: Universitas Negeri Malang, UM Press.

Bergen, C. (2020). The Conditional Legitimacy of Behavior Change Advice in Primary Care. Social Science \& Medicine, 255, 1-11.

Boyles, N. (2018). Learning Character from Characters. Educational Leadership, 76(2), 70-74.

Cheng, M. (2019). 8 Characteristics of Millennials That Support Sustainable Development Goals (SDGs), (Online), (https://www.forbes.com/sites/margueritacheng/2019/06/19/8-characteristics-of-millennials-thatsupport-sustainable-development-goals-sdgs/\#248956c429b7), diakses 31 Desember 2019.

deRuiter, J. A., Poorthuis, A. M. G., \& Koomen, H. M. Y. (2019). Relevant Classroom Events for Teachers: A Study of Student Characteristics, Student Behaviors, and Associated Teacher Emotions. Teaching and Teacher Education, 86, 1-12.

Dewantara, K. H. (2011a). Kebudayaan. Yogyakarta: Yayasan Persatuan Taman Siswa.

Dewantara, K. H. (2011b). Pendidikan. Yogyakarta: Yayasan Persatuan Taman Siswa.

Direktorat Pembinaan Sekolah Dasar. (2011). Panduan Pengembangan Pendidikan Karakter melalui Pembelajaran Aktif, Kreatif, Efektif dan Menyenangkan (Pakem) di Sekolah Dasar. Jakarta: Direktorat Jenderal Pendidikan Dasar, Kementerian Pendidikan dan Kebudayaan.

Dragomir, A. I., Julien, C. A., Bacon, S. L., Boucher, V. G., \& Lavoie, K. L. (2019). Training Physicians in Behavioural Change Counseling: A Systematic Review. Patient Education and Counseling, 102(1), 12-24.

Gunawan, I. (2011). Metode Kooperatif Model Think Pair Share, (Online), (http://masimamgun.blogspot. com/2010/06/metode-kooperatif-model-think-pair.html), diakses 3 Desember 2019.

Gunawan, I. (2013). Statistika untuk Kependidikan Sekolah Dasar. Yogyakarta: Penerbit Ombak Yogyakarta.

Gunawan, I. (2016). Pengantar Statistika Inferensial. Jakarta: Rajawali Pers.

Gunawan, I., Benty, D. D. N., Kusumaningrum, D. E., Sumarsono, R. B., Sari, D. N., Pratiwi, F. D., Ningsih, S. O., Putri, A. F., \& Hui, L. K. (2020). Pengaruh Gaya Kepemimpinan, Kemampuan Manajerial, Efikasi Diri, dan Prestasi Belajar terhadap Kesiapan Kerja Mahasiswa. JMSP (Jurnal Manajemen dan Supervisi Pendidikan), 4(2), 126-150.

Gunawan, I., Suminah, Murdiyah, S., Andriningrum, H., \& Onenda, G. (2018). Improving Student Learning Achievement through Behavior Modification Approach. Proceeding 1st International Conference on Early Childhood and Primary Education (ECPE 2018), Atlantis Press.

Gunawan, I., Ulfatin, N., Sultoni, S., Sunandar, A., Kusumaningrum, D. E., \& Triwiyanto, T. (2017). Pendampingan Penerapan Strategi Pembelajaran Inovatif dalam Implementasi Kurikulum 2013. Abdimas Pedagogi: Jurnal Ilmiah Pengabdian kepada Masyarakat, 1(1), 37-47.

Gunawan, I., Ulfatin, N., Sultoni, S., Sunandar, A., Kusumaningrum, D. E., \& Triwiyanto, T. (2016). Pendampingan Penerapan Strategi Pembelajaran Inovatif dalam Implementasi Kurikulum 2013 di MIS Lowokwaru Kota Malang. Laporan pengabdian kepada masyarakat tidak diterbitkan. Malang: Fakultas Ilmu Pendidikan Universitas Negeri Malang. 
Hadi, S., Gunawan, I., \& Dalle, J. (2018). Statistika Inferensial: Teori dan Aplikasinya. Jakarta: Rajawali Pers.

Hardika, Aisyah, E. N., \& Gunawan, I. (2018). Facilitative Learning to Improve Student Learning Creativity. Proceeding 3rd International Conference on Education Management and Administration (CoEMA 2018), Atlantis Press.

Hartini, H., Gunawan, I., \& Suraya, S. N. (2012). Persepsi Mahasiswa terhadap Kualitas Pelayanan Pendidikan FIP IKIP PGRI MADIUN. Jurnal Pendidikan, 18(1), 37-66.

Irfan, M. (2016). Role of Learning Mathematics in the Character Building. Proceedings of the International Conference on Education, Education in the 21th Century: Responding to Current Issues, Graduate School, Universitas Negeri Malang.

Kementerian Pendidikan dan Kebudayaan. (2017). Penguatan Pendidikan Karakter Jadi Pintu Masuk Pembenahan Pendidikan Nasional, (Online), (https://www.kemdikbud.go.id/main/blog/2017/07/penguatan-pendidikankarakter-jadi-pintu-masuk-pembenahan-pendidikan-nasional), diakses 31 Desember 2019.

Kementerian Pendidikan Nasional. (2010). Pengembangan Pendidikan Budaya dan Karakter Bangsa. Jakarta: Pusat Kurikulum, Badan Penelitian dan Pengembangan, Kemendiknas.

Kusumaningrum, D. E., Gunawan, I., Sumarsono, R. B., \& Triwiyanto, T. (2019b). Pendampingan Pengelolaan Perpustakaan untuk Mendukung Gerakan Literasi Sekolah. Abdimas Pedagogi: Jurnal Ilmiah Pengabdian kepada Masyarakat, 2(3), 164-169.

Kusumaningrum, D. E., Sumarsono, R. B., \& Gunawan, I. (2019a). Professional Ethics and Teacher Teaching Performance: Measurement of Teacher Empowerment with a Soft System Methodology Approach. International Journal of Innovation, Creativity and Change, 5(4), 611-624.

Lewis, B. A. (2017). The Kid's Guide to Service Projects: Over 500 Service Ideas for Young People Who Want to Make a Difference. New York: Free Spirit Publishing.

Liu, J., Zhu, Y., Serapio, M. G., \& Cavusgil, S. T. (2019). The New Generation of Millennial Entrepreneurs: A Review and Call for Research. International Business Review, 28(5), 1-10.

Mawarsari, V. D., \& Solichan, A. (2015). Upaya Peningkatan Kompetensi Mahasiswa melalui Pembelajaran Berkarakter dengan Pendekatan Inquiry Berbantuan Cabri 3d pada Geometri Ruang. Prosiding Seminar Nasional \& Internasional, Universitas Muhammadiyah Semarang.

McLean, L., Sparapani, N., Connor, C. M., \& Day, S. (2020). Students' Problem Behaviors and Teachers' Warmth and Demand as Predictors of Students' Classroom Instructional Experiences in First Grade. Contemporary Educational Psychology, 61, 1-12.

Nurabadi, A., Gunawan, I., \& Sari, Y. L. (2019). The Application of Informal Supervision to Improve the Quality of Learning in Laboratory Schools. Proceeding the 4th International Conference on Education and Management (COEMA 2019), Atlantis Press.

Pambudi, B. A., \& Gunawan, I. (2019). Instructional Leadership as an Effort to Increase Teacher Professionalism in the Industrial Revolution Era 4.0. Proceeding the 4th International Conference on Education and Management (COEMA 2019), Atlantis Press.

Prastiawan, A., Gunawan, I., Putra, A. P., Surahman, E., Dewantoro, D. A., Cholifah, P. S., \& Nuraini, N. L. S. (2019). Office Management of Educational Institutions: Theories and Applications. Proceeding 5th International Conference on Education and Technology (ICET 2019), Atlantis Press.

Putri, A. A. F., Putri, A. F., Andriningrum, H., Rofiah, S. K., \& Gunawan, I. (2019). Teacher Function in Class: A Literature Review. Proceeding the 5th International Conference on Education and Technology (ICET 2019), Atlantis Press.

Samsiyah, N., Kartikasari, A., Gunawan, I., \& Emilia, C. (2016). Konstruksi Tes Kebahasaan UAS SD di Kab. Madiun. Jurnal Penelitian LPPM (Lembaga Penelitian dan Pengabdian kepada Masyarakat) IKIP PGRI MADIUN, 2(1), 38-46.

Saputra, B. R., Adha, M. A., Ariyanti, N. S., \& Gunawan, I. (2019). Tips for Principal in Managing One Roof School (SATAP) in Underdeveloped Area. Proceeding the 4th International Conference on Education and Management (COEMA 2019), Atlantis Press.

Shen, H. H. (2005). An Investigation of Chinese-Character Learning Strategies among Non-Native Speakers of Chinese. System, 33(1), 49-68.

Sobri, A. Y., Bafadal, I., Nurabadi, A., \& Gunawan, I. (2018). Development of Mentoring Modules Based on SelfReflection for Beginner Principal. Proceeding the 3rd International Conference on Educational Management and Administration (CoEMA 2018), Atlantis Press. 
Sobri, A. Y., Bafadal, I., Nurabadi, A., \& Gunawan, I. (2019). Validity and Reliability of Questionnaire Problematics Leadership Beginner School Principals. Proceeding the 4th International Conference on Education and Management (COEMA 2019), Atlantis Press.

Sultoni, Gunawan, I., \& Ningsih, S. O. (2018a). Descriptive Study of Efforts Integrates Character Values to Students. Proceeding 3rd International Conference on Education Management and Administration (CoEMA 2018), Atlantis Press.

Sultoni, Gunawan, I., \& Pratiwi, F. D. (2018b). Perbedaan Motivasi Belajar Mahasiswa Antara Sebelum dan Sesudah Mengikuti Pelatihan Motivasional. Ilmu Pendidikan: Jurnal Kajian Teori dan Praktik Kependidikan, 3(1), 115-119.

Sumarsono, R. B., Kusumaningrum, D. E., Gunawan, I., Alfarina, M., Romady, M., Ariyanti, N. S., \& Budiarti, E. M. (2019). Training on the Implementation of Cooperative Learning Models as an Effort to Improve Teacher's Performance. Proceeding the 4th International Conference on Education and Management (COEMA 2019), Atlantis Press.

Suminah, Gunawan, I., \& Murdiyah, S. (2018). Peningkatan Hasil Belajar dan Motivasi Belajar Siswa melalui Pendekatan Behavior Modification. Ilmu Pendidikan: Jurnal Kajian Teori dan Praktik Kependidikan, 3(2), 221-230.

Tryanasari, D., Mursidik, E. M., \& Gunawan, I. (2013). Pengembangan Buku Pedoman Microteaching Berbasis Lesson Study Prodi PGSD FIP IKIP PGRI MADIUN. Jurnal Pendidikan, 19(1), 1-26.

Wing-YinChow, B. (2018). The Developmental Transition from Holistic to Analytic Character Learning in Child Readers of Chinese. Learning and Individual Differences, 67, 126-131.

Wiyono, B. B., \& Sunarni. (2009). Evaluasi Program Pendidikan dan Pembelajaran. Malang: Fakultas Ilmu Pendidikan Universitas Negeri Malang.

Wiyono, B. B., Kusumaningrum, D. E., Triwiyanto, T., Sumarsono, R. B., Valdez, A. V., \& Gunawan, I. (2019). The Comparative Analysis of Using Communication Technology and Direct Techniques in Building School Public Relation. Proceeding 2019 5th International Conference on Education and Technology (ICET) (hlm. 81-86). IEEE.

Yang, B., Yao, Z., Lu, H., Zhou, Y., \& Xu, J. (2020). In-Classroom Learning Analytics Based on Student Behavior, Topic and Teaching Characteristic Mining. Pattern Recognition Letters, 129, 224-231. 